\title{
Relationship Between Social, Technology, Personality, and Psychology Factors on Intention in Pre- Employment Training
}

\author{
Lina Affifatuholihah ${ }^{1 *}$,Farah Putri Wenang Lusianingrum ${ }^{2}$, Solehatin Ika Putri ${ }^{3}$ \\ 1,2,3 Universitas Sultan Ageng Tirtayasa, Serang, Indonesia \\ *Corresponding author. Email: lina@untirta.ac.id
}

\begin{abstract}
The Pre-employment Card Program was created as a solution for rising number of unemployment during the COVID 19 pandemic. The pre-employment card program has eight digital platform partners for online training delivery. There are various types of pre-employment card training. With more choices of types of training, managers and partners need to evaluate the factors that determine the decision to take online training for people who have a Pre-Employment Card in Indonesia. The research approach used is quantitative. The population of this research is people who have preemployment cards in Indonesia. The number of respondents in this study was 350 obtained by purposive sampling method. The SEM Warp PLS 7.0 application is used for statistical data calculations. The research results reveal that the factors that can influence the intention in participating in training for people who have a Pre-Employment Card in Indonesia are social, personality, technological, and psychological factors.
\end{abstract}

Keywords: Pre-employment card, pre-employment training, unemployment, covid-19.

\section{INTRODUCTION}

The amount of jobless people greater than before by 3.7 million people due to the pandemic in Indonesia. The government has made efforts to improve work competence by issuing a Pre-employment Card Program which is managed by the Coordinating Ministry for Economic Affairs assisted by other relevant ministries. This weakening economic activity encourages business actors to make efficiency by temporarily laying off (laying off). So, in March 2020 the government will quicken the launch of the Pre-employment Card Program to overcome the increase in TPT numbers due to the Covid-19 Pandemic. Apart from being intended for workers who have been laid off and temporarily dismissed, it is also for workers, job seekers, as well as small and micro business actors who need work competency development. So, the Pre-Employment Card Program is projected to be capable to reduce the TPT rate and increase the work competency of the workforce and workers [1].

The community empowerment program in the form of a Pre-Employment Card is one solution in order to improve skills for productive age who want to enter the world of work and economic independence which is managed by the Ministry of Manpower. The Pre- employment Card is a preparation fee support for Indonesians who wish to acquire or advance their skills. All citizens of the nation, both men and women aged 18 years and over and who are not currently attending school or college, can register themselves. This Preemployment Card is a form of cooperation between the government and the private sector in serving the community with the spirit of mutual cooperation, for the realization of superior human resources, innovative Indonesia.

The Ministry of Manpower then issued a training program as outlined in the Minister of Manpower Circular No. M / 3 / HK.04 / III / 2020 regarding the security of employees or labourers as well as corporate endurance in the situation of avoiding and overcoming Covid-19. The training programs include labourintensive environmental sanitation infrastructure, productive labour-intensive, entrepreneurship and the independent labour program.

Workers and the workforce who receive a PreEmployment Card are entitled to receive financial assistance for participating in job competency development training. The Coordinating Ministry for Economic Affairs as the manager has collaborated with the private sector and the government as partners for the 
implementation of online training. There are currently eight digital platform partners for conducting online training. These partners include Sisnaker, Pijar Mahir, Ruangguru, Pintaria, Bukalapak, and Tokopedia. The digital platform partner of the Pre-employment Card Program provides 1,338 types of training from business to self-development. Furthermore, there are still five digital platforms that submit proposals to be able to join as partners in the Pre-Employment Card Program and there are 362 new types of training proposed by partners.

The many types of training offered are beneficial for Pre-Employment Card holders to be able to choose the type of training according to their wishes. However, for partners this is a challenge in order to be able to make training according to the wants and needs of potential participants. Thus partners providing training conducted online need to reveal the factors determining the decision to take part in online training. This will help partners to be able to organize training according to the preferences of the Pre-Employment Card owner.

There are several researchers who adopt the model from Kotler and Keller that the determinants of decisions are consumer characteristics which include social, personality and cultural factors [2]-[6]. This study will also adopt a model from Kotler and Keller to determine the determining factors for the decision to take part in online training for Pre-Employment Card owners. However, this study also proposes additional factors, namely technology factors. This technology factor is considered relevant to be included in the model because the training aimed at Pre-Employment Card owners is conducted by digital platform partners. This digital platform partner will conduct training using a new system that is carried out online as well as a combination of online and offline training. The training model system based on information and communication technology is not so familiar to the community that adaptation is still needed in its implementation and is supported by the use of appropriate technology. Thus this research will try to reveal social, technological, personality, and psychology factors that influence the intention to participate in online training for PreEmployment Card owners.

\subsection{Hypothesis Formulation}

\subsubsection{The Influence of Social Factors on Intention in Participating in Online Training}

Social factors are a group of people who can be considered by someone in making a decision consisting of family, reference groups, and certain social status / roles [2], [3], [7]. The family is the first organization that plays an important role for a person. Parenting patterns, values, attitudes, and behavior of family members will shape experiences which become a factor for participants in making decisions. Furthermore, participants cannot be separated from joining the reference group which of course will have a direct or indirect impact on their behavior in making decisions. Finally, social status, where participants are seen to play a role in groups, families, associations, and organizations.

Participants who receive a Pre-Employment Card experience confusion in choosing the type of online training to participate in. Families and reference groups are appropriate sources of information and support to encourage participants to make decisions to take online training. Cheng et al. explained that individual intentions are influenced by the social factors they feel [3]. This is supported by Ko, a person will consider information and support from their social environment [8]. Thus, it can be formulated:

$\mathrm{H} 1$ : Social factors can influence intention in participating in online training

\subsubsection{The Influence of Personality Factors on Intention in Online Training}

According to Kotler and Keller personality factors are well-defined as psychological features of somebody who are diverse from others that cause moderately reliable and long-lasting responses to the surroundings [2]. Decisions to buy are also predisposed by personality features, namely time of life and life cycle stage, people adjustment the goods and services they purchase thru their life. Appetites for diet, outfit, stuff, and leisure are frequently related to age. Decisions to buy are also formed by the stages of the domestic product's life cycle, the stages that a family may go through according to its maturity.

Buying intention on the goods and services influence by occupations. Sellers attempt to classify job clusters that have beyond typical intentions of their goods and services. A corporation may even specify in marketing goods agreeing to explicit job-related groups. Further the current financial condition will influence the choice of products. The financial condition has an excessive effect on consumer buying behaviour. If their earnings and funds are great, they will purchase supplementary goods. However, if someone's' salary/earnings is low, they will buy low-priced products or they will not purchase at all [2].

An individual's life pattern is manifested in actions such as work, hobbies, shopping, sports, and social activities, and showed in intentions such as food, fashion, family and recreation. Lifestyle also displayed in opinions that are more than just social class and a person's personality, lifestyle displays reaction configurations and intermingle with someone as a whole in the domain. The last one is personality and Self Concept, everyone's personality clearly affects their buying behaviour. 
Unique psychological features that cause a relatively consistent and lasting response to one's own environment. His personality is usually described in terms of traits such as self-confidence, domination, sociability, autonomy, self-defence, adaptability, and aggressiveness [2]. Thus, it can be formulated:

$\mathrm{H} 2$ : Personality factors can influence intention in participating in online training

\subsubsection{The Influence of Technology Factors on Intention in Participating in Online Training}

These technological factors include perceived usefulness and perceived ease of use. Perceived usefulness relates to a person's level of belief regarding the use of a special system that will later improve job performance. It means that if someone later doubts the usefulness of a technology, then someone's intention will not appear to use it. So that if a woman has the belief that this online training will be of benefit to her, she will decide to take the training.

Furthermore, perceived ease of use is defined as the extent to which someone believes that the use of technology will be free from effort [9]. Perceptions of ease of use relate to the extent to which prospective users' expectations of the new system to be used are free from difficulties. In this case, when women made the decision to take part in the training, they believed that the online training system was easy to follow in the process of implementing it. This is in line with the results of research by Tarhini et al. and Sukla and Sharma that technological factors affect one's intensions [10][11]. Thus, it can be formulated:

H3: Technology factors can affect intention in participating in online training

\subsubsection{The Influence of Technology Factors on Intention in Participating in Online Training}

Kotler and Keller state that psychological factors are part of the influence of the environment in which they live and live at the present time without neglecting the influence of the past or their anticipation in the future. The choice of what a person buys is further influenced by important psychological factors. Motivation, a need that is sufficient to direct someone to find ways to satisfy a need. In order of importance, the level of needs is physiological needs, security needs, social needs, appreciation needs, and self-actualization recognition [2].

Perception is a process which persons decide on, unify and understand information to form an eloquent representation of the realm. An individual's driven is equipped to performance. Knowledge describes variations in separate behaviour that arise from understanding. Opinions and assertiveness concluded by exploit and learning, people gain beliefs and attitudes. All of these will distress purchasing behaviour. Attitude describes evaluations, feelings and tendencies of somebody towards knowledge or an item. That is relatively consistent. Assertiveness sets further persons in a setting of awareness about liking or disapproving something about imminent from it. Psychological factors are the most basic factors in an individual that will influence a person's choices in buying [2]. This is supported by the opinion of Kotler and Armstrong that perception is the process used by consumers to handpicked, establish, and deduce the input to enter motivational information that comes from within them where they think that rice is a need that must be met [12]. Thus, it can be formulated:

H4: Psychological factors can affect intention in participating in online training

\section{METHODS}

This study tries to use a quantitative approach as an effort to answer questions and research formulations. Data analysis was performed using primary data generated from online data collection. Data analysis was performed using the application Structural Equation Modelling Warp Partial Least Square (SEM Warp PLS) 7.0. Primary data were collected using 26 questions. The results of developing the research instrument will then be made into a questionnaire that will be submitted to people in Indonesia who meet the criteria online. Because only people who are intentioned in participating in pre-employment card training can be respondents, the method of determining the sample used is purposive sampling. The guidelines established to be respondents in this research are to have a preemployment card and Indonesian citizens. The minimum number of respondents is 350 people. This is consistent with Hair, Black, Babin, and Anderson (2014) that at least the number of samples used is ten times the number of statements or questions that represent each variable observed in the study [13].

\section{RESULTS AND DISCUSSION}

\subsection{RESULT}

Data analysis using SEM Warp PLS 7.0 was carried out in two steps. The first step is to test the validity and reliability of the instruments used or usually called the measurement model. Furthermore, the second step is to test the proposed hypothesis which is called the structural model. This are the results of the first step, namely the measurement model.

Table 1 shows that the statement items used in the study amounted to twenty-six items. Furthermore, the results 
of the convergent validity test contained two statement items whose factor loading values were lowered by 0.7 . Thus, the data analysis shows that all items valid. Furthermore, table 2 illustrates the results of the discriminant validity test where the root value of AVE is higher than the correlation between variables so that it meets the discriminant variables.

Table 1. Convergent Validity

\begin{tabular}{|c|c|c|}
\hline Items & Factor Loading & Validity \\
\hline \multicolumn{3}{|c|}{ Social Factors (S) } \\
\hline FS1 & 0.786 & Valid \\
\hline FS2 & 0.785 & Valid \\
\hline FS3 & 0.677 & Valid \\
\hline FS4 & 0.811 & Valid \\
\hline FS5 & 0.602 & Valid \\
\hline FS6 & 0.786 & Valid \\
\hline \multicolumn{3}{|c|}{ Personality Factors (K) } \\
\hline FK1 & 0.823 & Valid \\
\hline FK2 & 0.766 & Valid \\
\hline FK3 & 0.799 & Valid \\
\hline FK4 & 0.818 & Valid \\
\hline FK5 & 0.774 & Valid \\
\hline \multicolumn{3}{|c|}{ Technology Factors (T) } \\
\hline FT1 & 0.653 & Valid \\
\hline FT2 & 0.657 & Valid \\
\hline FT3 & 0.660 & Valid \\
\hline FT4 & 0.698 & Valid \\
\hline \multicolumn{3}{|c|}{ Psychological Factors (P) } \\
\hline FP1 & 0.677 & Valid \\
\hline FP2 & 0.686 & Valid \\
\hline FP3 & 0.694 & Valid \\
\hline FP4 & 0.663 & Valid \\
\hline FP5 & 0.699 & Valid \\
\hline FP6 & 0.676 & Valid \\
\hline \multicolumn{3}{|c|}{ Intentions (M) } \\
\hline MH1 & 0.633 & Valid \\
\hline MH2 & 0.681 & Valid \\
\hline MH3 & 0.662 & Valid \\
\hline MH4 & 0.699 & Valid \\
\hline MH5 & 0.648 & Valid \\
\hline
\end{tabular}

Table 2. Discriminant Validity

\begin{tabular}{|c|c|c|c|c|c|}
\hline Variables & $\mathbf{S}$ & $\mathbf{K}$ & $\mathbf{T}$ & $\mathbf{P}$ & $\mathbf{M}$ \\
\hline $\mathrm{S}$ & 0.752 & & & & \\
\hline $\mathrm{K}$ & 0.346 & 0.753 & & & \\
\hline $\mathrm{T}$ & 0.543 & 0.335 & 0.826 & & \\
\hline $\mathrm{P}$ & 0.414 & 0.344 & 0.667 & 0.811 & \\
\hline $\mathrm{M}$ & 0.485 & 0.462 & 0.635 & 0.633 & 0.833 \\
\hline
\end{tabular}

Finally, table 3 reveals that the five variables used, the value of cronbach's alpha and composite reliability, are greater than 0.7 , so it can be said to be relevant.

Table 3. Reliability

\begin{tabular}{|r|c|c|c|}
\hline Variables & $\begin{array}{c}\text { Cronbach } \\
\text { Alpha }\end{array}$ & $\begin{array}{c}\text { Composite } \\
\text { Reliability }\end{array}$ & Reliability \\
\hline $\mathrm{S}$ & 0.840 & 0.883 & Reliable \\
\hline $\mathrm{K}$ & 0.806 & 0.866 & Reliable \\
\hline $\mathrm{T}$ & 0.843 & 0.895 & Reliable \\
\hline $\mathrm{P}$ & 0.895 & 0.920 & Reliable \\
\hline $\mathrm{M}$ & 0.889 & 0.919 & Reliable \\
\hline
\end{tabular}

The second step of testing with SEM Warp PLS 7.0 is a structural model. The structural model in this study will be implemented to test the four hypotheses that have been proposed. The following is a picture of the structural model and the results of hypothesis testing. Figure 1 illustrate that all hypothesis are accepted because the coefficient $\beta=0.25$; $p$-Value $<0.001$. So when the cultural factor increases, the decision to follow will increase.

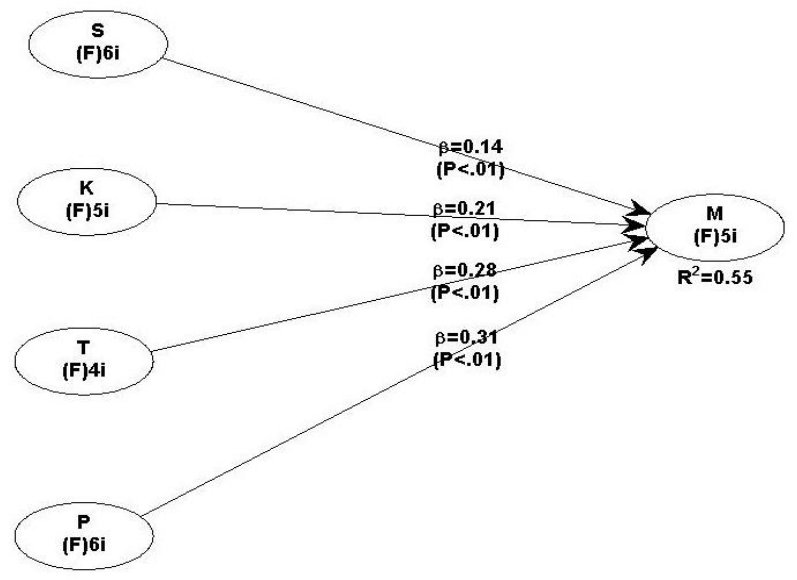

Figure 1. Research Model

Table 4. Model Summary

\begin{tabular}{|c|c|c|c|}
\hline Path & coefficient & p Value & Effect Size \\
\hline$S \rightarrow M$ & 0.14 & $p<0.001$ & 0.070 \\
\hline $\mathrm{K} \rightarrow \mathrm{M}$ & 0.21 & $\mathrm{p}<0.001$ & 0.104 \\
\hline $\mathrm{T} \rightarrow \mathrm{M}$ & 0.28 & $\mathrm{p}<0.001$ & 0.175 \\
\hline $\mathrm{P} \rightarrow \mathrm{M}$ & 0.31 & $\mathrm{p}<0.001$ & 0.200 \\
\hline \multicolumn{4}{|c|}{ Goodness of Fit Model } \\
\hline APC & 0.233 & $p<0.001$ & \\
\hline ARS & 0.549 & $p<0.001$ & \\
\hline AVIF & 1.727 & $p<0.001$ & \\
\hline
\end{tabular}


Table 4 shows that the AVIF value is smaller than 5 so that this research model is free from multicollinearity. In addition, the average path coefficient (APC) and average R-Square (ARS) values are also significant at the $1 \%$ level. Thus it can be said that the model developed by this study is proven to be good because it has met the three criteria of goodness of fit model, namely AVIF, APC, and ARS.

Figure 1 and table 4 illustrate that hypothesis 1 is accepted because the coefficient $\beta=0.14$; $p$-Value $<0.001$. So when social factors increase by one unit, intention in following will increase by 0.14 . This means that social factors are proven to increase intention in participating in online training for Pre-Employment Card holders. The acceptance of hypothesis 1 further strengthens the evidence that social factors play a role in determining an intention, including the intention in taking online training. This is also supported by Cheng et al. and Ko (2018) who prove social factors can support one's intentions. The values of social class, family, religion, and society where a person comes from will have an impact on their behaviour and attitudes, including in intentions [3][8]. Moreover, women in this case will tend to prioritize decision making by not violating these values.

Furthermore, the results of hypothesis 2 test show that the $\beta$ coefficient is positive at 0.21 and a significant p-value $<0.001$. These results indicate that personality factors influence the intention in participating in training for the Pre-employment Card owner. This supports the research of Pradhan et al., and Bosnjak et al. which proves that personality factors are important factors that affect a person's attitude and behaviour in determining intentions [14][4]. The intention taken by a woman is inseparable from the lifestyle she usually lives daily.

Hypothesis 3, namely the technology factor has a coefficient value of $\beta=0.28$ and is significant at the $1 \%$ level, which means that the hypothesis is accepted. This concurs by $\mathrm{Lu}$ et al. and Handarkho stated that a person's intention in making decisions is determined by technological factors [15][5]. Decisions are also influenced by the perceived benefits of applying technology to the new system. In this case, it is online training using a digital platform. Apart from the benefits, what was being considered was how easy it was to apply the technology to the new system. When implementing online training with a digital platform is considered easier and more flexible, it makes users intentioned in taking online training.

Finally, the results of hypothesis test 4 show that the $\beta$ coefficient is positive at 0.31 and a significant $p$-value $<0.001$. These results indicate that psychological factors influence the intention in participating in training for Pre-Employment Card owners. This supports the research of Donald et al., and Pilkington et al. which proves that psychological factors are an important factor influencing one's intentions [6][16]. The intentions of a person cannot be separated from motivation, perceptions, attitudes and beliefs.

\subsection{Discussion}

There are several previous researchers who adopted the model from Kotler and Keller that the determinants of interest are consumer characteristics which include social, personal, and cultural factors $[2][3][8][14][4][5][15][6][16]$. Therefore, this study will adopt a model from Kotler and Keller to determine the determinants of interest in participating in online training for Pre-Employment Card owners. However, this study proposes additional factors, namely technology factors.

This study analyses factors that influence intentions of pre-employment card owners in participating online training that conducted in Indonesia. The test results using SEM Warp PLS show that all research items are valid and reliable and show that all hypotheses are accepted. Therefore, social, personality, technology and psychological factors positively affect the intention of pre-employment card owners in participating online training. Compared with the results of previous studies conducted by Cheng et al., Ko , Pradhan et al., Bosnjak et al., Lu et al., Handarkho, Donald et al. and Pilkington et al., the results of this study support previous studies $[3][8][14][4][15][5][6][16]$.

Social factors can affect interests, namely friends, family, and social status. The results of this study prove that each individual has several people around him who influence him in doing something. The reference group consists of the people to which the individuals match themselves to one another. This includes friends, family members and relatives. Thus, a person tends to take part in the types of online pre-employment training recommended by his reference group [2][3][8].

Technology factor is considered relevant to be included in the model because the training aimed at PreEmployment Card owners is conducted by digital platform partners. The training model system based on information and communication technology is not so familiar to the community that adaptation is still needed in its implementation and is supported by the use of appropriate technology. Thus this study will try to reveal the impact of social, personality, technology and psychological aspects on the interest in participating online training for Pre-Employment Card owners [2][5][15].

Personality factors are the emotional features of somebody. Personality factors is different from others reasons a moderately steady and lifelong response to the atmosphere. In this study, a person's interest in participating in online pre-employment training is predisposed by particular features, namely: time of life, 
financial condition, and daily life. The age and lifestyle of a person may make a difference in interest in following this type of training online. Likewise, the amount of balance on someone's pre-employment card will influence training choices [2][14][4]

The last is the psychological factor, which is fragment that influenced by the situation in which someone's lives in the present-day deprived of neglecting the effect of the previous or its anticipation for the forthcoming. Psychological factors that influence interest in participating in online training are motivation, perception, knowledge, and beliefs. Motivation, perceptions, knowledge and beliefs of a person influence interest in participating in online preemployment training because they arise from the learning experiences they have [2][6][16].

\section{CONCLUSION AND SUGGESTION}

\subsection{Conclusion}

Grounded by statistical calculations using the SEM PLS 7.0 application, the variables of social, personality, technology and psychology factors partially affect the intention in participating in online training for PreEmployment Card owners in Indonesia. Furthermore, the four variables which include social factors, personality, technology and psychology simultaneously have a significant effect on the intention in participating in online training for pre-employment card owners by $55 \%$ though the respite is determined by variables that not analysed in this paper.

\subsection{Suggestion}

The outcomes of this paper are projected to be used as literacy regarding the determinants of intention in participating in online training by pre-employment card managers and digital platform partners when planning and implementing online training and determining the type of training.

\section{AUTHORS' CONTRIBUTIONS}

The design and implementation of the research based on social, technology, personality, and psychology factors on intention, and also the analysis of the results. Critical criticism and abetted shape the research, analysis and manuscript was provided by all authors.

\section{ACKNOWLEDGMENTS}

LPPM Universitas Sultan Ageng Tirtayasa was fully supported this research. We thank our colleagues from Diploma III Marketing Program that providing comprehension and knowledge. Our colleagues had also impressively supported this research. While we discussed a lot with all of the interpretations and conclusions of this paper. We thank to all respondents for the participation in this research, and reviewer from LPPM for notes that critically upgraded the manuscript.

\section{REFERENCES}

[1] Badan Pusat Statistik, Keadaan Ketenagakerjaan Indonesia Februari 2020. 2020.

[2] P. Kotler and K. L. Keller, MarkKotler, P., \& Keller, K. L. (2016). Marketing Management. Global Edition (Vol. 15E). https://doi.org/10.1080/08911760903022556eti ng Management. 2016.

[3] P. Y. Cheng and M. C. Chu, "Behavioral Factors Affecting Students' Intentions to Enroll in Business Ethics Courses: A Comparison of the Theory of Planned Behavior and Social Cognitive Theory Using Self-Identity as a Moderator," J. Bus. Ethics, vol. 124, no. 1, pp. 35-46, 2014, doi: 10.1007/s10551-013-1858-0.

[4] M. Bosnjak, M. Galesic, and T. Tuten, "Personality determinants of online shopping: Explaining online purchase intentions using a hierarchical approach," J. Bus. Res., vol. 60, no. 6, pp. 597-605, 2007, doi: 10.1016/j.jbusres.2006.06.008.

[5] Y. D. Handarkho, "The intentions to use social commerce from social, technology, and personal trait perspectives: analysis of direct, indirect, and moderating effects," J. Res. Interact. Mark., vol. 14, no. 3, pp. 305-336, 2020, doi: 10.1108/JRIM-10-2018-0137.

[6] I. J. Donald, S. R. Cooper, and S. M. Conchie, "An extended theory of planned behaviour model of the psychological factors affecting commuters' transport mode use," J. Environ. Psychol., vol. 40, pp. 39-48, 2014, doi: 10.1016/j.jenvp.2014.03.003.

[7] J. P. Peter and J. C. Olson, Consumer Behavior \& Marketing Strategy. 2009.

[8] H. C. Ko, "Social desire or commercial desire? The factors driving social sharing and shopping intentions on social commerce platforms," Electron. Commer. Res. Appl., vol. 28, pp. 1-15, 2018, doi: 10.1016/j.elerap.2017.12.011.

[9] I. Im, S. Hong, and M. S. Kang, "An international comparison of technology adoption: Testing the UTAUT model," Inf. Manag., vol. 48, no. 1, pp. 1-8, 2011, doi: 10.1016/j.im.2010.09.001.

[10] A. Tarhini, K. Hone, and X. Liu, "Measuring 
the moderating effect of gender and age on Elearning acceptance in England: A structural equation modeling approach for an extended Technology Acceptance Model," J. Educ. Comput. Res., vol. 51, no. 2, pp. 163-184, 2014, doi: 10.2190/EC.51.2.b.

[11] A. Shukla and S. K. Sharma, "Evaluating Consumers' Adoption of Mobile Technology for Grocery Shopping: An Application of Technology Acceptance Model," Vision, vol. 22, no. 2, pp. 185-198, 2018, doi: 10.1177/0972262918766136.

[12] P. Kotler and G. Amstrong, Principles of Marketing Global. 2012.

[13] J. F. Hair, W. C. Black, B. J. Babin, and R. E. Anderson, "Multivariate Data Analysis," Vectors. 2010, doi: 10.1016/j.ijpharm.2011.02.019.

[14] D. Pradhan, I. Duraipandian, and D. Sethi, "Celebrity endorsement: How celebrity-branduser personality congruence affects brand attitude and purchase intention," J. Mark. Commun., 2016, doi: 10.1080/13527266.2014.914561.

[15] J. L. Lu, H. Y. Chou, and P. C. Ling, "Investigating passengers' intentions to use technology-based self check-in services," Transp. Res. Part E Logist. Transp. Rev., 2009, doi: 10.1016/j.tre.2008.09.006.

[16] A. Pilkington, R. M. Msetfi, and R. Watson, "Factors affecting intention to access psychological services amongst British Muslims of South Asian origin," Ment. Heal. Relig. Cult., 2012, doi: 10.1080/13674676.2010.545947. 